Article

\title{
Surface Functionalization of an Aluminum Alloy to Generate an Antibiofilm Coating Based on Poly(Methyl Methacrylate) and Silver Nanoparticles
}

\author{
Lisa Muñoz ${ }^{1, *}$, Laura Tamayo ${ }^{2}$, , Miguel Gulppi ${ }^{1}$, Franco Rabagliati ${ }^{1}$, Marcos Flores ${ }^{3}$, \\ Marcela Urzúa ${ }^{2}$, Manuel Azócar ${ }^{1}{ }^{\circledR}$, Jose H. Zagal ${ }^{1}$, María V. Encinas ${ }^{1}$, Xiaorong Zhou ${ }^{4}$, \\ George Thompson ${ }^{4}$ and Maritza Páez ${ }^{1, *}$ \\ 1 Departamento de Química de los Materiales, Facultad de Química y Biología, Universidad de Santiago \\ de Chile, Av. L. B. O’Higgins 3363, Casilla 40, Correo 33, Santiago 9170022, Chile; \\ miguel.gulppi.c@usach.cl (M.G.); franco.rabagliati@usach.cl (F.R.); manuel.azocar@usach.cl (M.A.); \\ jose.zagal@usach.cl (J.H.Z.); maria.encinas@usach.cl (M.V.E.) \\ 2 Departamento de Química, Facultad de Ciencias, Universidad de Chile, Las Palmeras 3425, Nuñoa, \\ Santiago 7800024, Chile; lauratamayo26@gmail.com (L.T.); maurzua@uchile.cl (M.U.) \\ 3 Laboratory of Surface and Nanomaterials, Physics Department, Faculty of Physics and Mathematics Science, \\ Universidad de Chile, Beauchef 850, Santiago 8370415, Chile; mflorescarra@ing.uchile.cl \\ 4 Corrosion and Protection Centre, School of Materials, The University of Manchester, Manchester M13 9PL, \\ UK; xiaorong.zhou@manchester.ac.uk (X.Z.); george.thompson@manchester.ac.uk (G.T.) \\ * Correspondence: lisa.munozm@usach.cl (L.M.); maritza.paez@usach.cl (M.P.); Tel.: +56-22-718-3426 (L.M.)
}

Received: 18 September 2018; Accepted: 22 October 2018; Published: 24 October 2018

check for updates

\begin{abstract}
An experimental protocol was studied to improve the adhesion of a polymeric poly(methyl methacrylate) coating that was modified with silver nanoparticles to an aluminum alloy, AA2024. The nanoparticles were incorporated into the polymeric matrix to add the property of inhibiting biofilm formation to the anticorrosive characteristics of the film, thus also making the coating antibiocorrosive. The protocol consists of functionalizing the surface through a pseudotransesterification treatment using a methyl methacrylate monomer that bonds covalently to the surface and leaves a terminal double bond that promotes and directs the polymerization reaction that takes place in the process that follows immediately after. This results in more compact and thicker poly(methyl methacrylate) (PMMA) coatings than those obtained without pseudotransesterification. The poly(methyl methacrylate) matrix modified with nanoparticles was obtained by incorporating both the nanoparticles and the methyl methacrylate in the reactor. The in situ polymerization involved combining the pretreated AA2024 specimens combined with the methyl methacrylate monomer and AgNps. The antibiofilm capacity of the coating was evaluated against P. aeruginosa, with an excellent response. Not only did the presence of bacteria decrease, but the formation of the exopolymer subunits was $99.99 \%$ lower than on the uncoated aluminum alloy or the alloy coated with unmodified poly(methyl methacrylate). As well and significantly, the potentiodynamic polarization measurements indicate that the PMMA-Ag coating has a good anticorrosive property in a $0.1-\mathrm{M}$ $\mathrm{NaCl}$ medium.
\end{abstract}

Keywords: coating; antibiofilm; functionalization; poly(methyl methacrylate); aluminum alloy

\section{Introduction}

A coating that protects a surface has two interfacial regions; one faces the metal surface, namely the metal-coating interface, and the other faces the environment, namely the coating-environment interface. In the first, surface-coating adhesion plays a determining role, while in the second, the adhesion of 
environmental species (chemical and biological) to the surface of the coating is crucial. Influencing the two interfaces can enhance the durability of the coating and extend the useful life of the coated surface. There are several factors that affect adhesion and involve, on the one hand, the composition and morphology of the metal surface, which is closely related to the metallurgical history of the metal substrate [1,2], and on the other hand, the surface pretreatments of the metal before applying the coating $[3,4]$.

Various treatments have been developed to improve adhesion on aluminum surfaces. The most widely used is conversion coating, which is based on chromate species. However, this approach is subject to increasingly stringent environmental regulations, which has spurred efforts to develop alternatives; these efforts have not had good results to date [5,6]. Coating adhesion is not only an issue with aluminum alloys; attempts have been made to improve the adhesion of coatings on other metal surfaces such as zinc. In fact, a recent publication reports using vinyltrimethoxysilane (VTS) as a pretreatment to functionalize oxidized zinc substrates. The functionalized zinc was then subjected to the thermally initiated copolymerization of methyl methacrylate (MMA) in the presence or absence of crosslinkers, resulting in a coating of poly(methyl methacrylate) [PMMA]. Although PMMA coatings have high levels of mechanical strength, thermal stability, and corrosion resistance, cathodic delamination is evident over time due to the hydrolysis of the siloxane bond in the inorganic polymer matrix $[7,8]$. There is currently major interest in research into directly bonding coatings to surfaces [7-10].

In relation to the coating environment, a series of factors have been studied to inhibit or limit the interaction of coatings with environmental species [11]; among these is the effect of the hydrophilic or hydrophobic character on the anti-adhesive performance of polymer coatings [12,13].

Considering the harmful effects of bacterial colonization and the potential applications of coatings in other areas, such as biomedicine, we wanted to expand the properties and applications of PMMA coating. PMMA is a polymer that is widely used in implantable medical devices due to its biocompatible characteristics, low inflammatory reaction, and easy processability. PMMA also has good resistance to ultraviolet light and to attack by chemical agents that are widely used in the manufacture of pneumatic actuators for pumping fluids [14]. However, PMMA is highly susceptible to bacterial colonization [15]. Faced with this problem, antibiotics have been incorporated into implants, which has been a widely-used method to prevent bacterial colonization and infection. However, the ability of bacteria to resist antibiotics poses major problems with respect to their use [16]. In this respect, new antibacterial substances that minimize bacterial resistance represent an alternative strategy. Metallic nanoparticles of silver, copper, and gold are being used as an alternative to antibiotics because of their excellent antibacterial capacity [17-19], broad spectrum of effectiveness, and low bacterial resistance [20]. The incorporation of nanoparticles in different polymer matrices has allowed the development of new antibacterial materials with excellent results in implants, medical devices, and membranes for water treatment [21,22].

This work proposes an experimental protocol for covalently bonding a PMMA-AgNps coating to an aluminum alloy surface. The protocol is termed pseudotransesterification, since it involves the esterification of the prehydroxylated metal surface, to finally bond the monomer methyl methacrylate (MMA) and then grow an AgNp-modified film by radical polymerization to prevent the delamination of the polymeric film and adhesion of microorganisms.

\section{Results and Discussion}

\subsection{Characterization of the Functionalized Aluminum Alloy Surface}

X-ray photoelectron spectroscopy (XPS) was used to characterize the AA2024 aluminum alloy after the pseudotransesterification treatment. The XPS spectra are shown in Figures 1 and 2. 

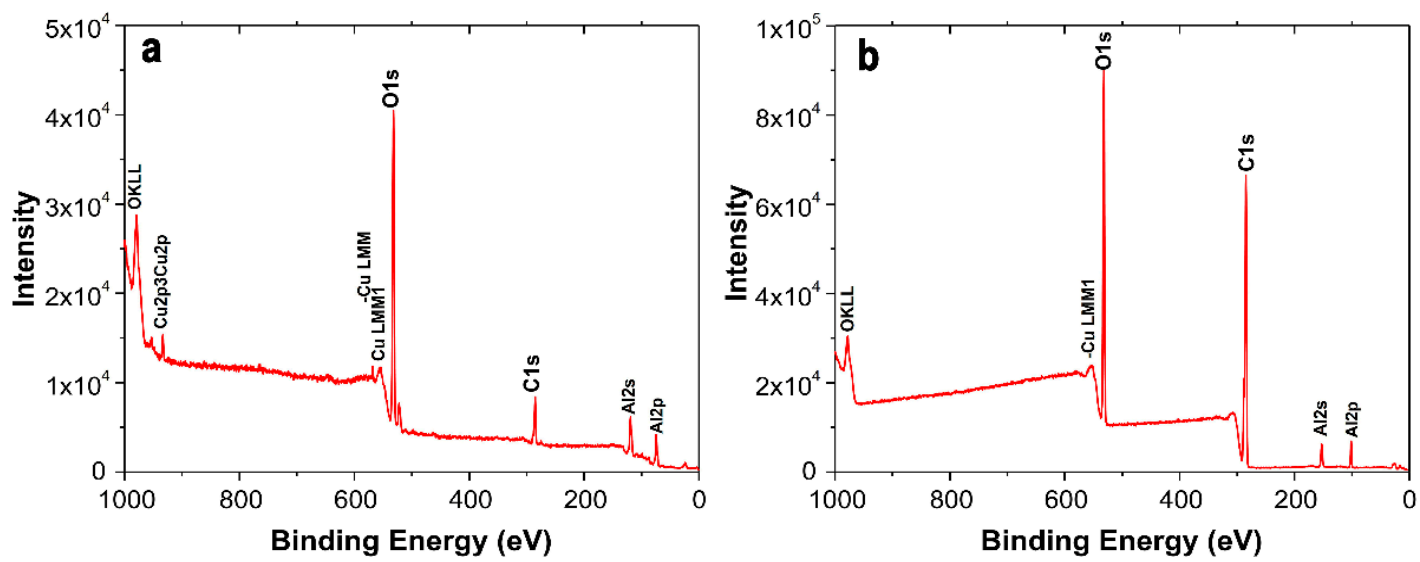

Figure 1. X-ray photoelectron spectroscopy (XPS) spectra of the differently pretreated AA2024 aluminum alloy: (a) chemically etched (AA); (b) chemically etched and pseudotransesterification treated (AA-TE).

Figure 1 shows the survey XPS spectra of chemically etched (termed hereafter AA) and pseudotransesterification treated (termed hereafter as AA-TE) AA2024 aluminum alloy. The effect of pseudotransesterification is reflected in the significantly decreased value of the O1s:C1s intensity peaks. The ratio with pseudotransesterification is $2: 3$, while it is $1: 5$ without the treatment. This result was expected, since the presence of the methyl methacrylate monomers on the surface increases the photoelectron yields of carbon species. Changes were also expected in the oxygen peak O1s, where the hydroxyl group $(-\mathrm{OH})$, which is located at $532.1(\mathrm{eV})$ [23], participates in the modification reaction by exchanging the methoxy $\left(-\mathrm{OCH}_{3}\right)$ group of the methyl methacrylate monomer with the $\mathrm{Al}-\mathrm{OH}$ group on the metal surface. The deconvolution of the high-resolution O1s spectra of samples AA and AA-TE is shown in Figure 2.
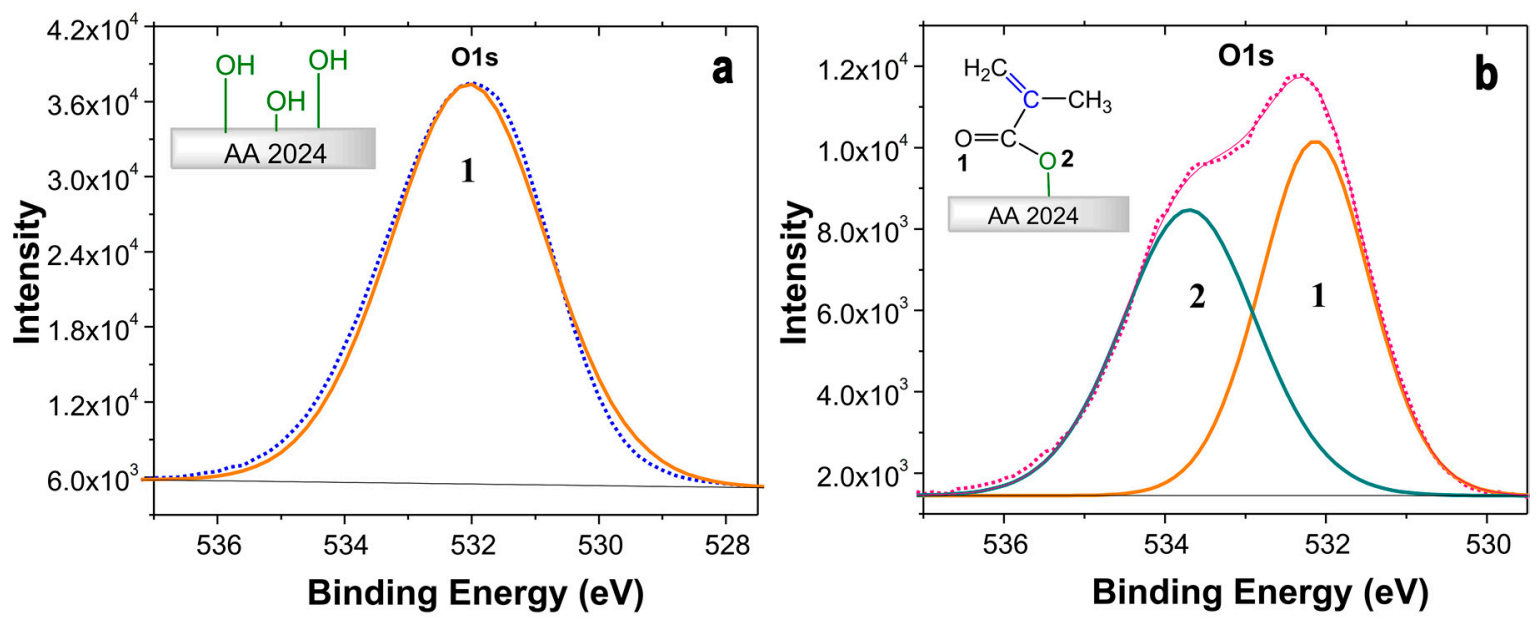

Figure 2. XPS spectra showing the O1s peaks on the aluminum alloy: (a) chemically etched (AA); (b) chemically etched and pseudotransesterification treated (AA-TE).

Figure 2a shows the fit of the O1s peak on the surface of the chemically etched aluminum alloy, revealing the $\mathrm{OH}$ group at $531.9 \mathrm{eV}$, corresponding to the hydroxylated alumina. In contrast, Figure $2 \mathrm{~b}$ shows the deconvolution of the O1s peak obtained from the aluminum alloy with pseudotransesterification treatment, revealing two O1s peaks. Peak 1 represents the oxygen of the carboxyl group $(532.1 \mathrm{eV})$ that is present in methyl methacrylate [24], where the unreacted hydroxyl groups (-OH) appear to contribute to the intensity. Peak 2, at $533.6 \mathrm{eV}$, represents the oxygen that is bonded directly to aluminum. 
In order to verify the pseudotransesterification of the aluminum alloy surface, we used $\alpha$-alumina powder as the benchmark for the surface oxide layer on the aluminum alloy. Through the E/I curves obtained by differential pulse voltammetry, we observed that the alumina colloid with the pseudotransesterification treatment presented two current peaks at -0.51 and $-0.83 \mathrm{~V}$, which are associated with the reduction of carbonyl carbon, demonstrating that pseudotransesterification occurred on $\alpha$-alumina particulates. These peaks were not observed for the colloidal system containing alumina without the pseudotransesterification treatment (see Supplementary Materials).

\subsection{Morphological Characterization of the Coated Aluminum Alloy}

Following the pseudotransesterification treatment, the PMMA coating was achieved by mass radical polymerization (Scheme 1 ).

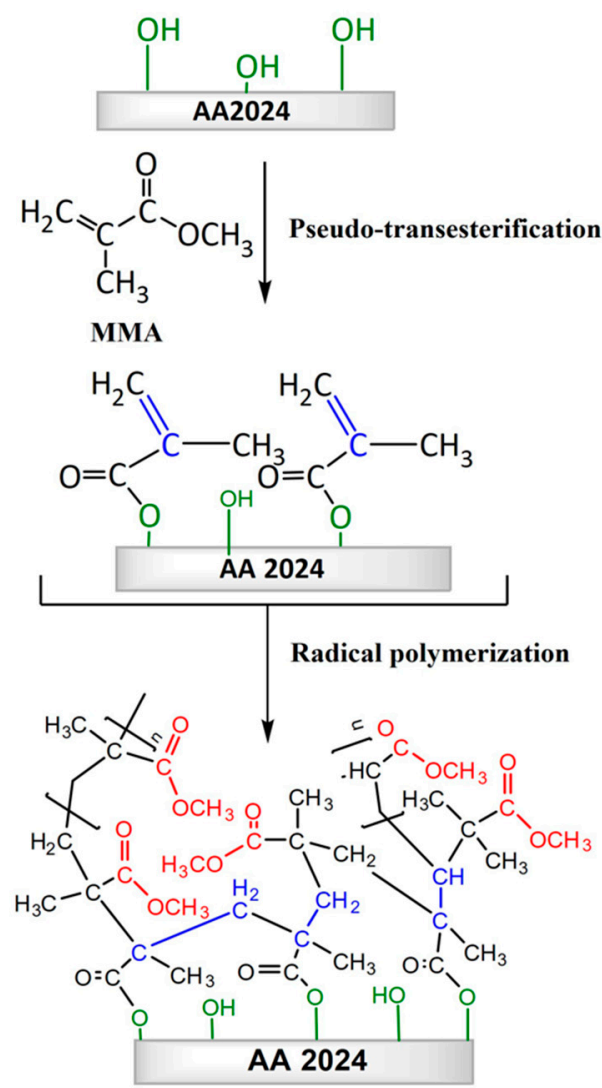

Scheme 1. Scheme of the surface modification steps.

The poly(methyl methacrylate) [PMMA] coating on the aluminum alloy surface was characterized by scanning electron microscopy (SEM). Figure 3 shows SEM micrographs of the coated alloy surfaces with 45-min, 90-min, and 120-min polymerization treatments. Figure 3(a1,b1,c1) shows the chemically-etched coated alloy without functionalizing with pseudotransesterification. The coating exhibits surface porosity with the presence of cluster-like material. Figure 3(a2,b2,c2) shows the PMMA coatings on the aluminum alloy with the pseudotransesterification treatment. The images show that the surface is smoother and without pores. The insets on each subfigure are images of the cross-section of the coatings. 

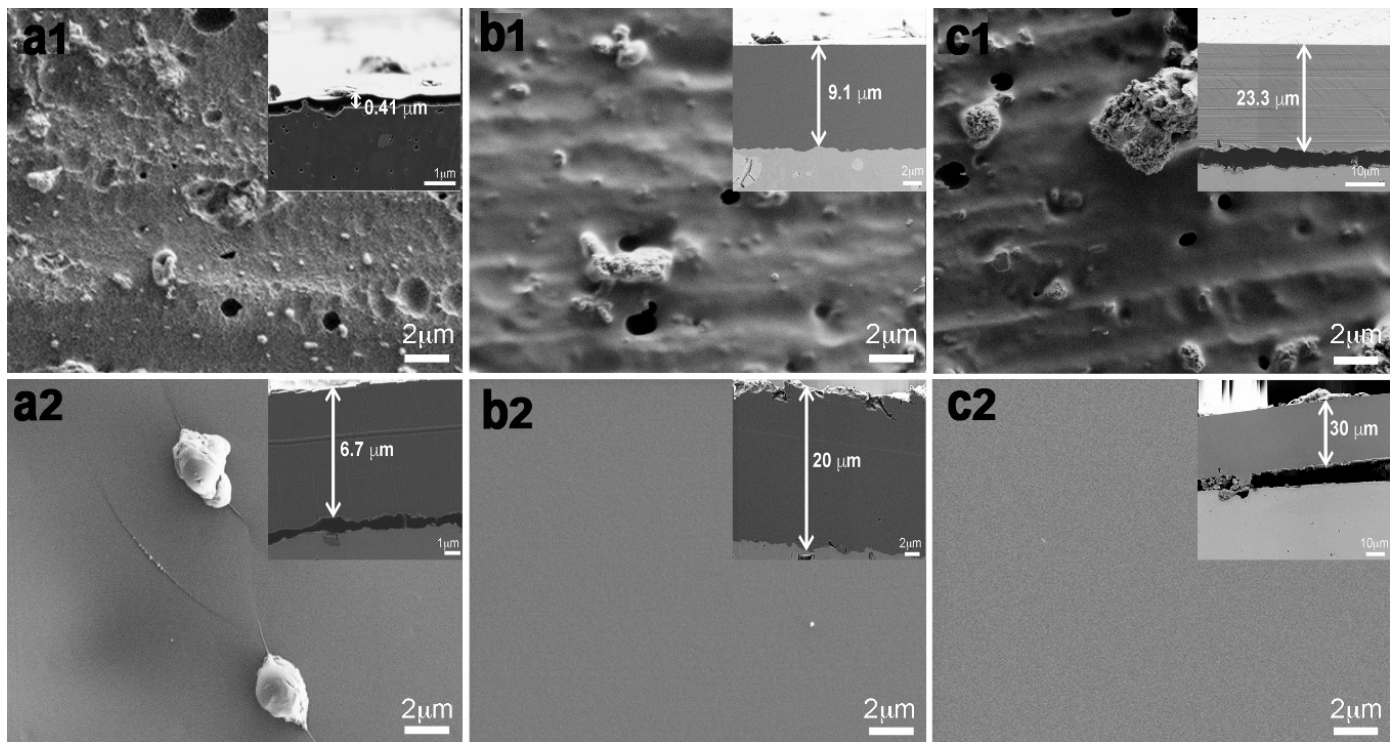

Figure 3. SEM micrographs and cross-sections of the AA2024 alloy coated by radical polymerization treatment, without pseudo-transesterification; (a1) AA-PMMA 45'; (b1) AA-PMMA 90'; (c1) AA-PMMA $120^{\prime}$ and with pseudo-transesterification; (a2) AA-PMMA 45'; (b2) AA-TE-PMMA 90'; and (c2) AA-TE-PMMA $120^{\prime}$.

Pseudotransesterification promotes polymerization reactions on the alloy with the resulting formation of thicker coatings on the functionalized surface than on the surfaces of untreated alloys, as demonstrated by the results that are presented in Figure 4 for a coated alloy surface with a 90-min polymerization treatment. SEM micrographs of the cross-sections reveal the dependence of the coating formation on the surface pretreatment. It is evident that thicker coatings are formed on the alloy surface that is functionalized by the pseudotransesterification treatment.
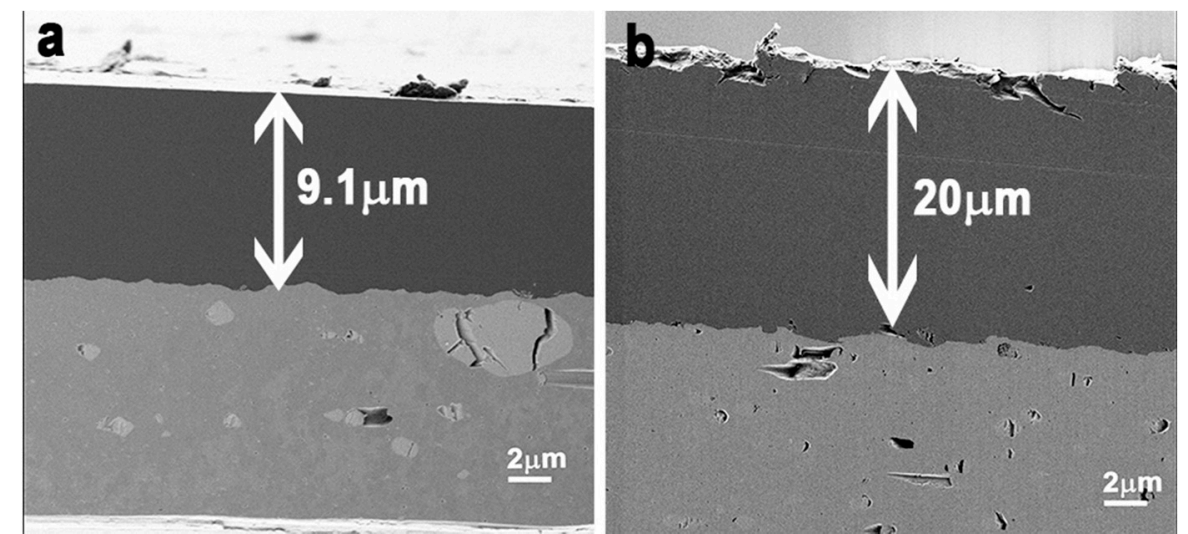

Figure 4. SEM micrographs of the cross sections of the alloy surface and its coatings: (a) AApoly(methyl methacrylate) (PMMA) 90' and (b) AA-TE-PMMA 90'.

\subsection{Characterization of the Coating Surfaces by XPS}

Figure 5 shows the XPS spectra with the O1s peak from the poly(methyl methacrylate) and the O1s peak obtained from the aluminum alloy coated with poly(methyl methacrylate) film. 

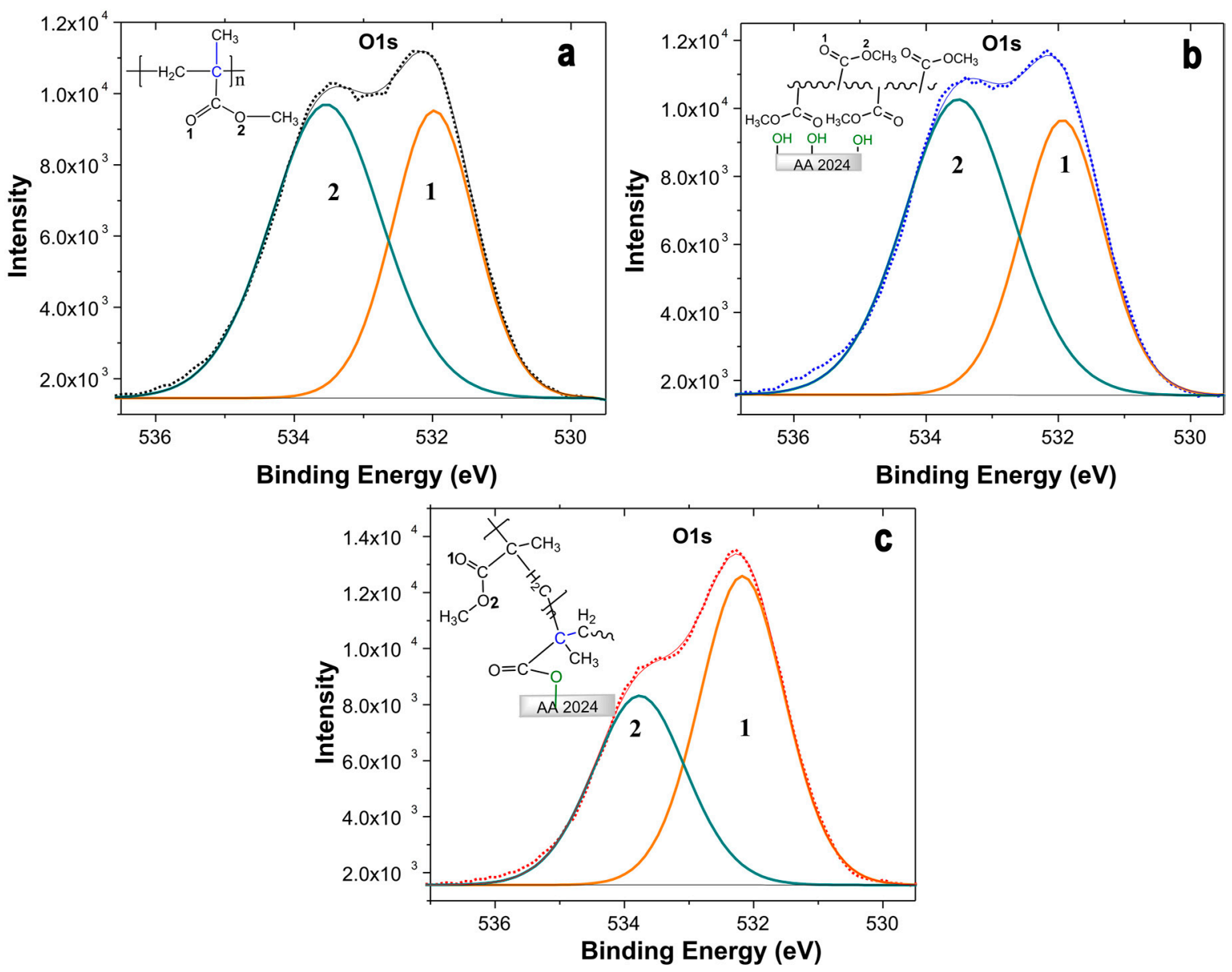

Figure 5. XPS spectra showing the O1s peaks of: (a) Poly(methyl methacrylate), (b) aluminum alloy coated with poly(methyl methacrylate) (AA-PMMA), and (c) aluminum alloy modified with pseudotransesterification and then polymerized with methyl methacrylate (AA-TE-PMMA).

Table 1 shows the area relationships of the O1s peaks of the different PMMA modifications. Figure 5a shows the non-functionalized PMMA signals where two main components are observed; $\mathrm{O}=\mathrm{C}$ group (1) at a binding energy of $531.9 \mathrm{eV}$, and group OC (2) at a binding energy of $533.4 \mathrm{eV}$. The $\mathrm{O}=\mathrm{C} / \mathrm{OC}$ concentration ratio was extracted from the O1s signals. At $45 / 56$, the ratio was very close to the value of 48/52 in the literature [25-27].

The AA-PMMA samples show almost equal amounts of $\mathrm{O}=\mathrm{C}$ and $\mathrm{O}-\mathrm{C}$, as observed in the peaks in Figure $5 b$, where the $\mathrm{O}=\mathrm{C} / \mathrm{O}-\mathrm{C}$ concentration ratio was $42 / 58$, which is very similar to that of the PMMA samples (Figure 5a). In the case of the alloy treated with pseudotransesterification (AA-TE), the $\mathrm{O}-\mathrm{C}$ bonds gradually decreased, and the $\mathrm{O}=\mathrm{C}$ bonds increased significantly, as can be seen in Figure $2 \mathrm{~b}$, with an $\mathrm{O}=\mathrm{C} / \mathrm{O}-\mathrm{C}$ ratio of $57 / 43$. This effect was the same with the aluminum surface modified by pseudotransesterification and subsequently polymerized (AA-TE-PMMA) (Figure 5c), where the highest number of $\mathrm{O}=\mathrm{C}$ bonds (59\%) was detected, and the concentration ratio was 59/41.

Table 1. O1s peak area of oxygen plasma-treated PMMA.

\begin{tabular}{ccc}
\hline Sample & O1s (1) O=C (\%) & O1s (2) O-C (\%) \\
\hline PMMA & 45 & 56 \\
AA-PMMA & 42 & 58 \\
AA-TE & 57 & 43 \\
AA-TE-PMMA & 59 & 41 \\
\hline
\end{tabular}


The effect of the conformation of polymer chains in the XPS spectra has been investigated experimentally and theoretically [28]. It has been proposed that changes in the orientation of the functional groups of a polymer chain significantly affect the XPS spectra [27]. The pseudotransesterified sample in Figure 5 reveals differences in the signal intensity of 1 s oxygen on the surface. The schematic model of the surface molecule (on the right side of the spectrum, Figure $5 \mathrm{c}$ ) shows a more exposed $\mathrm{O}=\mathrm{C}$ bond, which could explain why the oxygen intensity of this bond is higher than that of the O-C bond. It is possible that pseudotransesterification influences the growth/order process of the polymer at the surface. In contrast, the growth of the polymer on the non-transesterified sample could be disorderly at the surface, with an exposure in the same proportion of the $\mathrm{O}=\mathrm{C}$ and $\mathrm{O}-\mathrm{C}$ oxygen bonds (schematic model, on the left side of the spectrum in Figure $2 b$ ).

\subsection{Contact Angle Measurements}

Figure 6 shows the contact angle profiles obtained for AA2024, AA2024 + TE, AA2024 + TE + PMMA, and PMMA with $0.01 \mathrm{wt} \%$ and $1 \mathrm{wt} \%$ of silver nanoparticles. It can be observed that AA2024 is the most hydrophilic surface, with the lowest contact angle $\left(49.0^{\circ}\right)$, which increases slightly with the pseudotransesterification treatment $\left(69.7^{\circ}\right)$, while AA2024 coated with PMMA has the highest contact angle values $\left(100.4^{\circ}\right.$ and $\left.104.2^{\circ}\right)$, as has been observed in other works [29]. However, no significant influence could be observed of the pseudotransesterification treatment on the hydrophobicity of the coating. The hydrophobic character decreases in the presence of AgNPs, with contact angle values of $89.8^{\circ}$ and $86.7^{\circ}$ for PMMA with $0.01 \mathrm{wt} \%$ and $1 \mathrm{wt} \%$ of AgNPs, respectively.

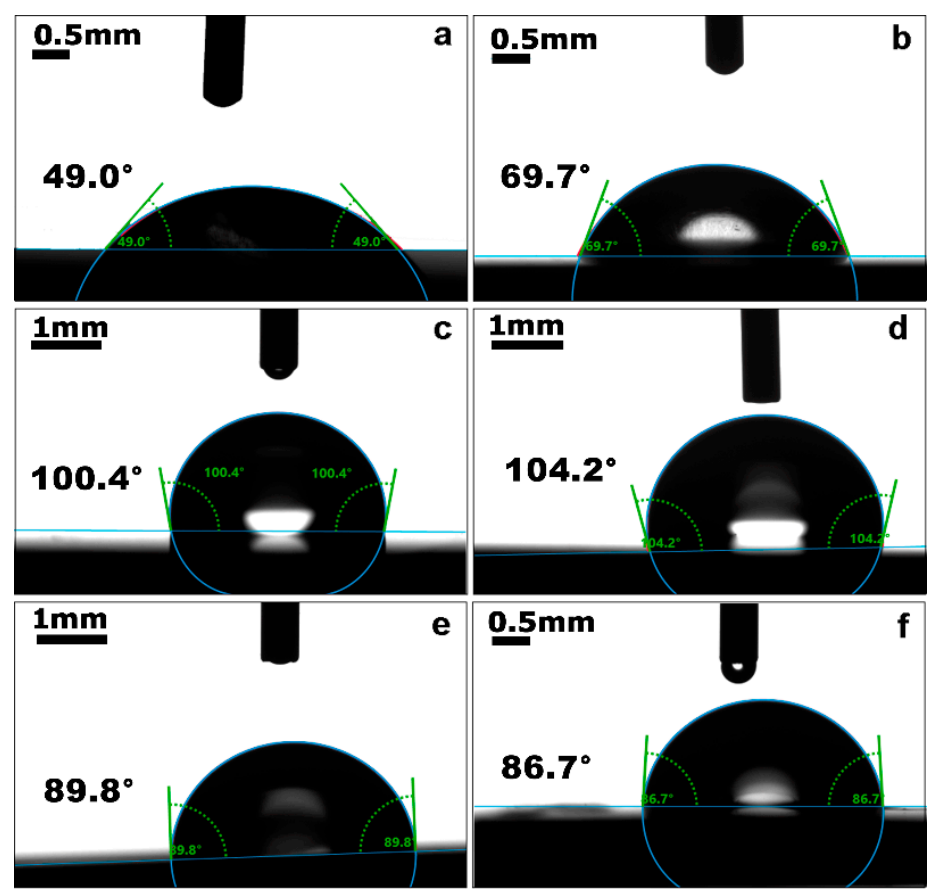

Figure 6. Contact angle of (a) AA2024, (b) AA2024 + TE, (c) AA2024 + PMMA, (d) AA2024 + TE + PMMA, (e) AA2024 + TE + PMMA-Ag $0.01 w t \%$, and (f) AA2024 + TE + PMMA-Ag $1 w t \%$.

\subsection{Antibacterial Properties of Coatings}

Figure 7 shows SEM images of Pseudomonas aeruginosa incubated for $24 \mathrm{~h}$ on an aluminum alloy without coating (AA2024), an aluminum alloy with treatment (AA2024 + TE), an aluminum alloy with coating (AA2024 + PMMA), and an aluminum alloy with treatment and coating (AA2024 + TE + PMMA). Pseudomonas aeruginosa biofilm can be observed on AA2024 and AA2024 + TE. Other authors have reported the formation of biofilm on aluminum, where SEM images have shown bacteria embedded in a layer of extracellular polymeric substances (EPS) on aluminum, which is 
similar to what can be observed in Figure 7 [30]. In contrast, when Pseudomonas aeruginosa is incubated on AA2024 coated with PMMA, the bacterial morphology changes, and EPS is not observed. Studies have shown that Pseudomonas aeruginosa adheres less to hydrophobic than hydrophilic surfaces [31]. The same effects of hydrophilicity/hydrophobicity on bacterial adhesion can be observed in our results.

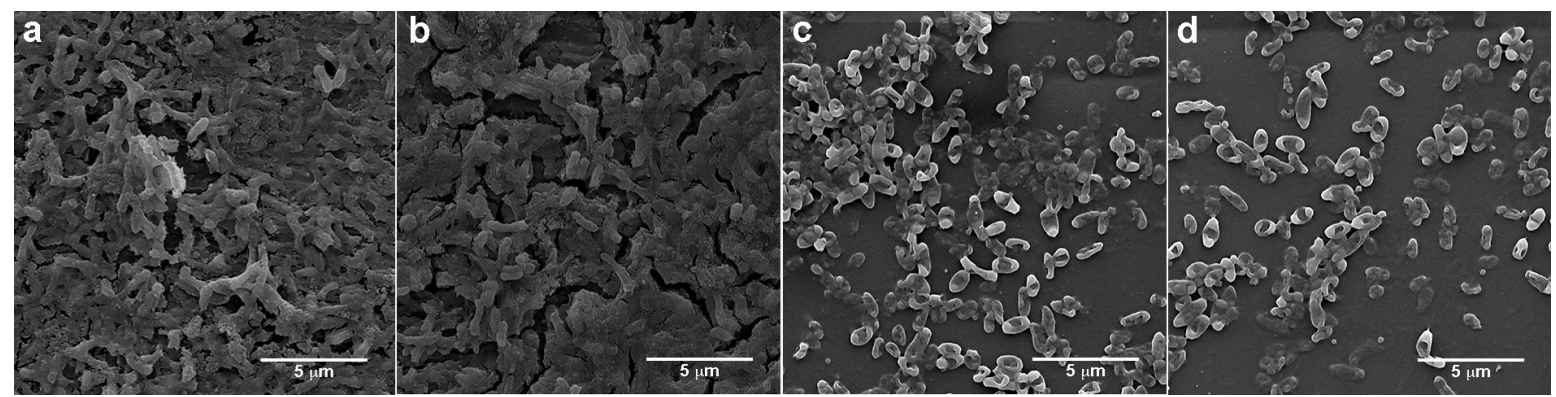

Figure 7. Pseudomonas aeruginosa incubated for $24 \mathrm{~h}$ on (a) AA2024, (b) AA2024 + TE, (c) AA2024 + PMMA, and (d) AA2024 + TE + PMMA.

To make the PMMA responsive against bacterial proliferation, we incorporated AgNPs into the PMMA coating by in situ polymerization. Figure 8 shows TEM images of the AgNPs in PMMA. AgNPs with sizes between 5-10 nm can be observed, and with good dispersion.

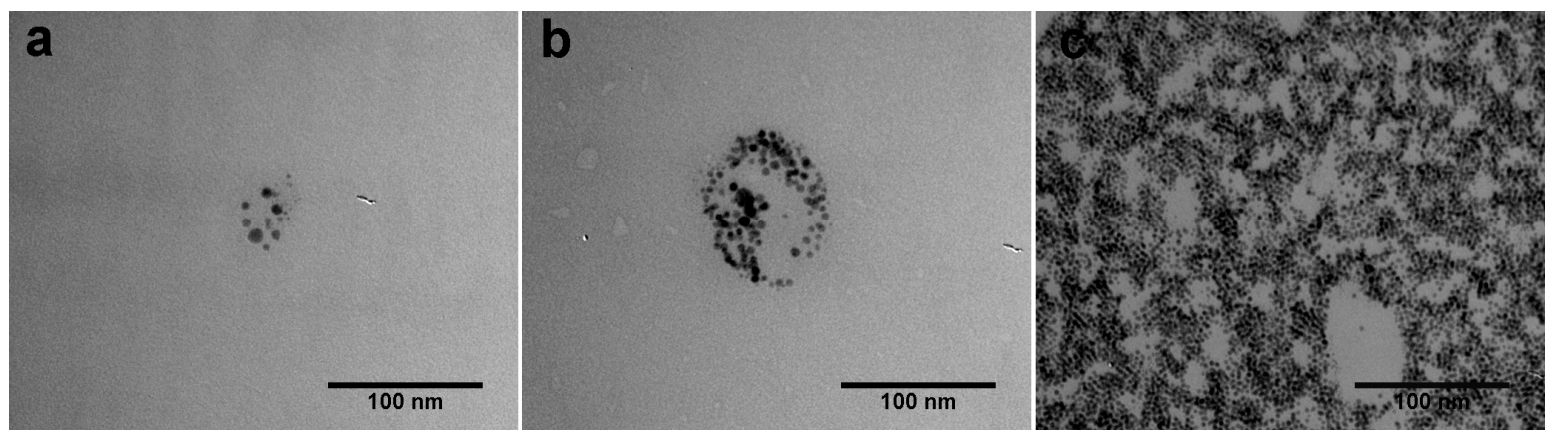

Figure 8. TEM images of (a) PMMA-AgNPs $0.01 \mathrm{wt} \%$, (b) PMMA-AgNPs $0.1 \mathrm{wt} \%$, and (c) PMMA-AgNPs $1 \mathrm{wt} \%$.

The incorporation of AgNPs in the PMMA coating changed the behavior against Pseudomonas aeruginosa. We evaluated the antibiofilm capability of the PMMA coating with three quantities of AgNPs; $0.01 \mathrm{wt} \%, 0.1 \mathrm{wt} \%$, and $1 \mathrm{wt} \%$ (Figure 9). The presence of silver in the coating was confirmed by EDS analysis (Figure 9e,f). Few bacteria were observed on PMMA-AgNPs $0.01 \mathrm{wt} \%$ (red circle), while no bacteria were observed on PMMA-Ag $0.1 \mathrm{wt} \%$ and PMMA-Ag $1 \mathrm{wt} \%$. Additionally, we evaluated the bacterial viability of Pseudomonas aeruginosa on aluminum alloy with and without coating. The results showed an inhibition of $99.99 \%$ of bacterial colonies for AA2024 + TE + PMMA-Ag containing $0.01 \mathrm{wt} \%$ of AgNPs, while that AA2024 + TE + PMMA and AA2024 showed an inhibition of $11.4 \mathrm{wt} \%$ and $0.01 \mathrm{wt} \%$, respectively (see Figure $\mathrm{S} 3$ in the Supplementary Data).

The antibacterial property of AgNPs is associated with the release of silver ions. Other works have reported that silver ions bind to proteins in the plasma membrane of the bacteria, and alter their permeability. Silver ions also bind to and condense DNA, preventing it from replicating. Another mechanism of silver ions is generating reactive oxygen species (ROS) that alter the metabolic processes of bacteria and the integrity of their membranes [17,32]. 

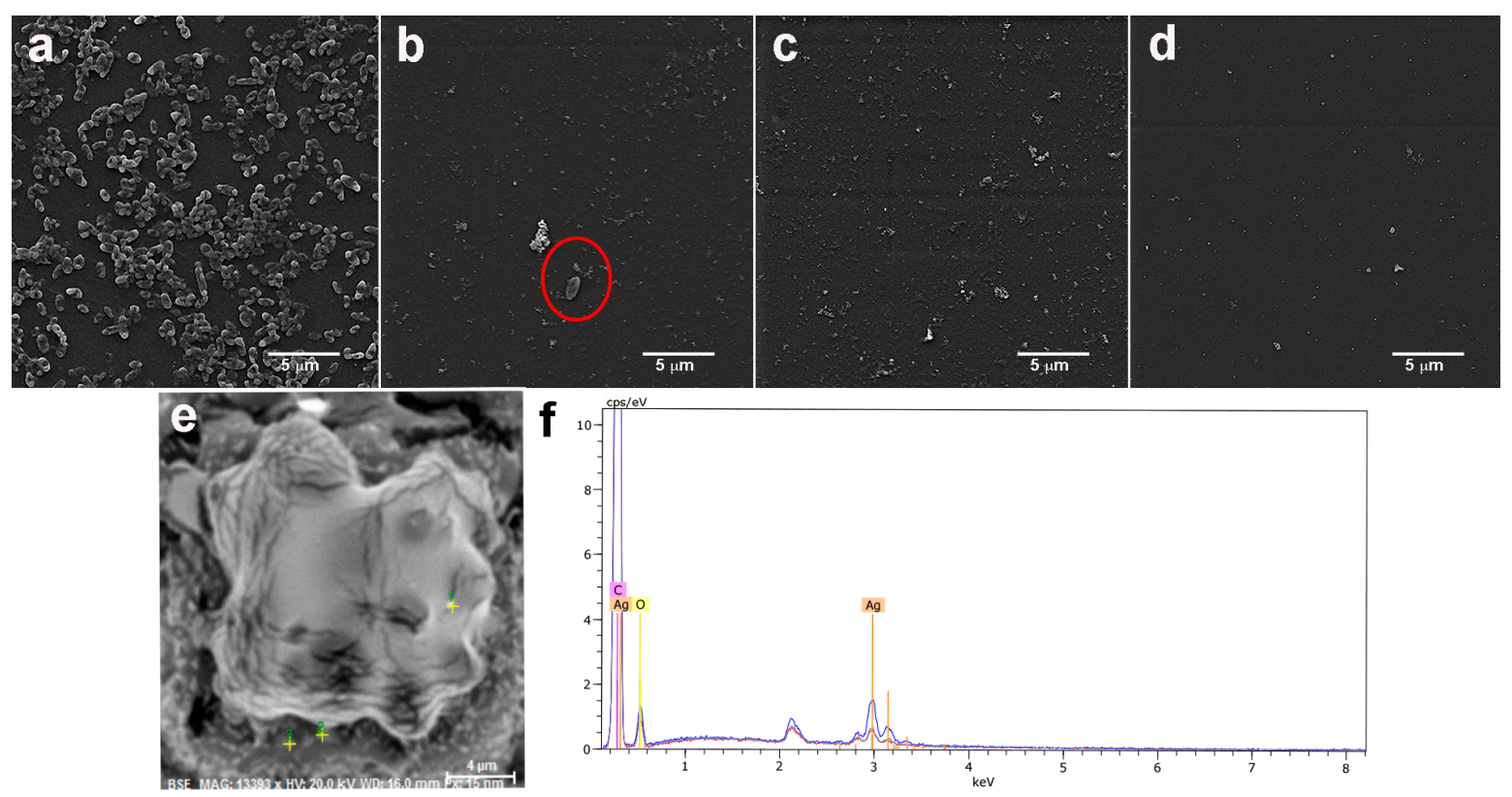

Figure 9. Pseudomonas aeruginosa incubated for $24 \mathrm{~h}$ on (a) AA2024 + TE + PMMA, (b) AA2024 + TE + PMMA-Ag $0.01 w t \%$, (c) AA2024 + TE + PMMA-Ag 0.1 wt \%, (d) AA2024 + TE + PMMA-Ag $1 w t \%$,

(e) AA2024 + TE + PMMA-Ag $1 \mathrm{wt} \%$ analyzed by EDS (1, 2, 3 correspond to each measurement point),

(f) EDS spectrum.

\subsection{Effect of Pseudotransesterification on the Protective Capability of Coatings}

In order to evaluate the protective capacity of the polymeric coatings, the potential current responses of the differently coated aluminum samples were studied in $0.1 \mathrm{M}$ of $\mathrm{NaCl}$ and after exposure to electrolytes for $20 \mathrm{~h}$. Figure 10 shows the results.

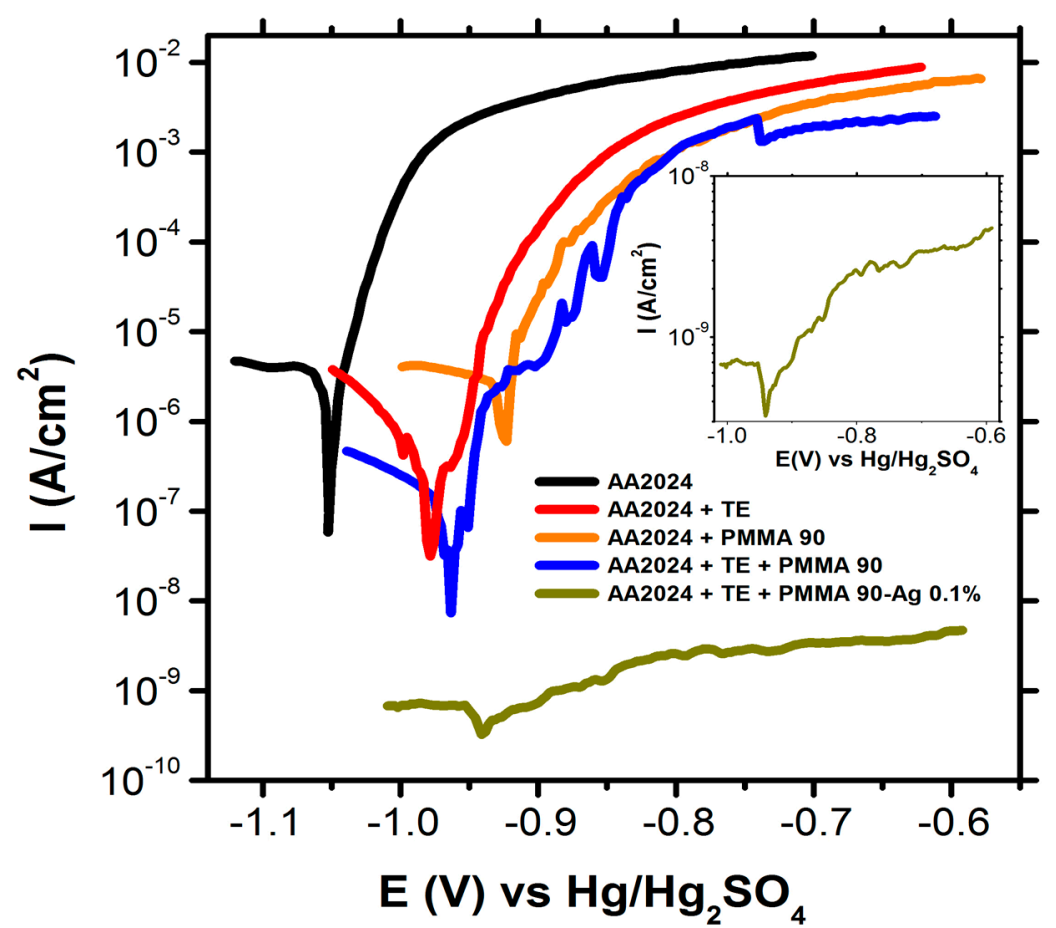

Figure 10. Anodic polarization curves of aluminum alloy surfaces differently treated and coated by polymers in $0.1 \mathrm{M}$ of $\mathrm{NaCl}$ at a sweep rate of $0.2 \mathrm{mV} \mathrm{s}^{-1}$. 
The corrosion parameters presented in Table 2 were obtained from the Evans diagrams based on the polarization curves in Figure 10.

Table 2. Open circuit potential, current, and inhibition efficiency of metal surfaces under different treatments obtained from Figure 8.

\begin{tabular}{cccc}
\hline Sample & OCP $\mathbf{~ V )}$ & $\mathbf{I}\left(\mathbf{A} / \mathbf{c m}^{\mathbf{2}}\right)$ & IE $(\%)$ \\
\hline AA & $-1.06 \pm 0.01$ & $4.4 \times 10^{-7}$ & n.d \\
AA + TE & $-0.97 \pm 0.01$ & $4.3 \times 10^{-8}$ & 90.0 \\
AA + PMMA & $-0.93 \pm 0.01$ & $5.9 \times 10^{-7}$ & n.d \\
AA + TE + PMMA & $-0.95 \pm 0.01$ & $7.1 \times 10^{-9}$ & 98.0 \\
AA2024 + TE + PMMA-Ag 0.1 wt $\%$ & $-0.94 \pm 0.02$ & $4.1 \times 10^{-10}$ & 99.0 \\
\hline
\end{tabular}

n.d: not determined.

The anodic curves in Figure 10 show that the current density decreases with pseudotransesterification, which could be related to the increased compaction of the coating (Figure 4). The decreased current density is an order of magnitude lower than the anodic currents of the bare surface, and two orders of magnitude lower than the surfaces coated with the polymer without anchoring. The current density of the coating with AgNPs was three orders of magnitude lower than the bare alloy, reaching a high inhibition efficiency of $0.99 \%$. The large passivation zone that was observed for coatings with AgNPs may be associated with the negative charge of the nanoparticles (zeta potential $=-38 \mathrm{mV}$ ), which generates electrostatic repulsion with the chloride ions in the corrosive medium. The low current density and high passivation region demonstrate that the film provides an efficient barrier against corrosion agents. The relationship between the compaction of the polymer coatings and the quality of the anticorrosive protection is well known $[33,34]$. Corrosion agents can diffuse through pores or cracks and reach the interface. In these regions, chemical changes can destabilize the polymer locally, and delaminate it. The build-up of stress in these regions can also result in mechanical damage to the polymer. In any case, chemical and mechanical damage results in sites in which aggressive species such as halides or organic acids in aqueous media catalyze the generation of pitting.

\section{Materials and Methods}

\subsection{Materials}

$p$-Toluenesulfonic acid (PTSA, 98\%), hydroquinone (HQ, 99\%) and calcium hydride $\left(\mathrm{CaH}_{2}\right.$, 95\%) were obtained from Aldrich (Santiago, Chile). Methyl methacrylate (MMA), benzoyl peroxide, nitric acid $(20 \% v / v)$, and methanol (P.A) were obtained from Merck (Santiago, Chile). The $\alpha$-alumina was obtained from Reich (Santiago, Chile), and aluminum alloy (AA2024) was provided by the National Aeronautics Company of Chile (Santiago) (ENAER).

\subsection{Surface Treatment of the AA2024 Aluminum Alloy}

The AA2024 aluminum alloy samples were mechanically polished with $\mathrm{SiC}$ grinding paper of 600 grits, 800 grits, 1200 grits, and 2400 grits, and then etched chemically according to the following sequence of steps: (i) immersed in a $0.1-\mathrm{M} \mathrm{NaOH}$ solution for two minutes; (ii) rinsed in deionized water; and then immediately (iii) immersed in a $\mathrm{HNO}_{3} 20 \% v / v$ solution for two minutes; (iv) rinsed in deionized water and dried in a cool air stream. All of the solutions were prepared with deionized water.

\subsection{Pseudotransesterification Process}

The AA2024 alloy and $\alpha$-alumina surfaces were modified in a distillation system. The MMA monomer, the catalyst PTSA, and hydroquinone were added to the distillation system in the presence of the aluminum alloy, which was previously hydroxylated, in the same manner as in the surface treatment of the above-described AA2024 aluminum alloy. The system was heated to $90{ }^{\circ} \mathrm{C}$ with 
stirring for $20 \mathrm{~h}$. The excess MMA was distilled off under reduced pressure. Specimens were then washed with methanol.

\subsection{Polymerization of Methyl Methacrylate on Aluminum Alloy}

The aluminum alloy was coated by mass radical polymerization using the MMA monomer to form a poly(methyl methacrylate) film on the alloy surface (Scheme 1). Prior to the polymerization treatment, the MMA monomer was washed with $5 \mathrm{wt} \% \mathrm{NaOH}$ solution, and dried with calcium hydride. MMA polymerization was carried out in a Schlenk reactor, loading the previously modified aluminum alloy sample (Section 2.3), prewashed MMA $(15 \mathrm{~mL})$, and benzoyl peroxide $(0.05 \mathrm{wt} / \mathrm{v} \%)$. The system was kept under stirring at $55^{\circ} \mathrm{C}$. In parallel, MMA was polymerized in the absence of the aluminum alloy sample in the same conditions as indicated above. For both cases, average molecular weights were determined by HPLC chromatography using a Hewlett Packard Series 1100 equipment (Waldbronn, Germany) with a refraction index as the detector, THF as the solvent, and a TSK-GEL $(7.5 \mathrm{~mm} \times 30 \mathrm{~cm})$ column. The values of $\mathrm{Mw}$ and $\mathrm{Mw} / \mathrm{Mn}$ that were obtained are $445.037 \mathrm{~g} / \mathrm{mol}$ and $1.2 \mathrm{~g} / \mathrm{mol}$, respectively.

\subsection{AgNPs Synthesis and PMMA-Ag Preparation}

AgNPs were prepared according to the method used by Wang [35], where $1 \times 10^{-3} \mathrm{M} \mathrm{AgNO}_{3}$ solution containing $1 \times 10^{-4} \mathrm{M}$ of oleic acid was mixed dropwise with $4 \times 10^{-4} \mathrm{M} \mathrm{NaBH}_{4}$ solutions. Then, $2 \mathrm{~mL}$ of $\mathrm{K}_{2} \mathrm{HPO}_{4}$ was added to $100 \mathrm{~mL}$ of AgNPs suspension together with $100 \mathrm{~mL}$ of toluene. AgNPs in the organic phase was rotaevaporated and added to a Schlenk reactor (Soviquim, Santiago, Chile) together with a prewashed MMA monomer $(5 \mathrm{~mL})$ and benzoyl peroxide $(0.05 w t / v \%)$ for polymerization reaction. The system was kept under stirring at $55{ }^{\circ} \mathrm{C}$. Silver nanoparticles were analyzed in a Philips Tecnai 12 TEM (Philips, Amsterdam, Netherlands).

\subsection{Surface Analysis}

XPS. The chemical states of the aluminum alloy following the treatment were investigated by X-ray photoelectron spectroscopy (XPS), using a Kratos Axis Ultra DLD (Kratos Analytical, Manchester, UK) at a takeoff angle of $45^{\circ}$, with monochromatic $\mathrm{Al} \mathrm{K}$ 年 radiation $(\mathrm{h} v=1486.6 \mathrm{eV})$ at $150 \mathrm{~W}$ and $1.0 \times 10^{-8}$ mbar at a pass energy of $23.5 \mathrm{eV}$. The energy resolution that was used was $0.2 \mathrm{eV}$. Samples were survey scanned for relevant elements (pass energy $=100 \mathrm{eV}$, energy step $=0.5 \mathrm{eV}$ ). The 1 s elemental peak was from carbon $(285 \mathrm{eV})$. The data was processed with CasaXPS, version 2.3.17 (House Software, Sanderland, UK).

SEM. The morphologies of the uncoated and coated aluminum alloy surfaces were investigated by scanning electron microscopy (SEM) using a Philips XL30 (Philips, Amsterdam, Netherlands) at an acceleration voltage of $5 \mathrm{kV}$. Cross-sections of the coated samples were cut by ultramicrotomy to characterize the surface-coating interface.

\subsection{Antibiofilm Assay}

The samples were inoculated with $100 \mu \mathrm{L}$ of bacterial suspension and incubated at $37^{\circ} \mathrm{C}$ for $16 \mathrm{~h}$. The samples were rinsed twice with $0.01 \mathrm{M}$ of sodium cacodylate $/ 0.15 \mathrm{M} \mathrm{NaCl}$ buffer at $\mathrm{pH} 7.0$ and fixed with $1 \%$ glutaraldehyde for $2 \mathrm{~h}$ at room temperature. Finally, the samples were dehydrated in ascending grades of ethanol $(30 \%, 50 \%, 70 \%, 80 \%, 90 \%$, and $100 \%)$, after which they were coated with a thin film of $\mathrm{Pt} / \mathrm{Pd}$ prior to being observed by SEM [19].

\subsection{Potentiodynamic Measurements}

Measurements were taken with a potentiostat-galvanostat (AUTOLAB PGSTAT30, Metrohm, Palm River-Clair-Mel, Fl, USA), and a standard three-compartment cell. Aluminum alloy AA2024 electrode plates were carefully prepared, leaving a $1-\mathrm{cm}^{2}$ area exposed to the electrolyte. The counter 
electrode was made of high purity platinum (99.99\%), and the reference electrode was made of mercury /mercuric sulfate $\left(\mathrm{Hg} / \mathrm{Hg}_{2} \mathrm{SO}_{4}\right)$ (SSE). The polarization curves were obtained in $0.1 \mathrm{M}$ of $\mathrm{NaCl}$, after $20 \mathrm{~h}$ of open circuit potential (OCP) stabilization time, at a scanning rate of $0.1 \mathrm{mV} / \mathrm{s}$ in the range of -70 to $+350 \mathrm{mV}$ versus the open-circuit potential (OCP). The inhibition efficiency (IE) of the coatings and functionalized surface was calculated using the following Equation (1):

$$
I E \%=\frac{i_{0}-i_{\text {corr }}}{i_{0}} \times 100
$$

where $i_{0}$ and $i_{\text {corr }}$ are the corrosion current densities of the surface and the surface-functionalized coatings, respectively, as determined by analysis of the Tafel plots.

\section{Conclusions}

Pseudotransesterification is a feasible metallic surface pretreatment to form covalent bonds with polymer coatings. XPS spectra reveal that the polymer on the transesterified specimen grows differently from that grown on the surface without pseudotransesterification. Thus, pseudotransesterification promotes polymerization reactions on alloys, resulting in coarser surface coatings. While the PMMA coating allowed the adhesion of Pseudomonas aeruginosa, the presence of AgNPs prevented biofilms from generating and bacteria from adhering. As well, the decrease in the anodic currents of the coatings, as compared to the bare AA2024, demonstrated the corrosion protection capacity of the coatings. Finally, the protective and antibiofilm features of this coating demonstrate that it is suitable for use in a variety of applications.

Supplementary Materials: The following are available online, Figure S1: Schematic diagram showing pseudo-transesterification of the $\alpha$-alumina particulates with methyl methacrylate (MMA) (* PTSA: $p$-toluenesulfonic acid), Figure S2: Differential pulse voltammetry of different alumina colloid suspensions in $0.1 \mathrm{M} \mathrm{NaOH}$. Colloid M1: $150 \mathrm{ppm}$ of $\mathrm{Al}_{2} \mathrm{O}_{3}$ particles; Colloid M2: $150 \mathrm{ppm}$ of $\mathrm{Al}_{2} \mathrm{O}_{3}$ particles after being immersed in a solution of MMA monomer and washed with methanol; Colloid M3: 150, 450 and 950 ppm of $\mathrm{Al}_{2} \mathrm{O}_{3}$ particles with pseudo-transesterification treatment, Figure S3: Viability of Pesudomonas aeruginosa incubated on (a) AA2024, (b) AA2024 + PMMA and (c) AA2024 + TE + PMMA-AgNPs 0.01 wt $\%$.

Author Contributions: L.M. conceived, designed and performed the experiments; M.G. designed the differential pulse voltammetry experiments; L.T. performed antibiofilm assays; M.F. analyzed XPS the data; M.U., and M.P. analyzed the data; L.M. and L.T. wrote the paper; M.U., M.A., F.R., J.H.Z., M.V.E., G.T., X.Z. and M.P. revised the manuscript critically for important content. All authors read and approved the final manuscript.

Funding: This research was funded by PIA-CONICYT grant number ACT1412, Dicyt-USACH (project 051742PC-DAS), FONDECYT Initiation grant 11160230 and PAI-CONICYT 79170015.

Conflicts of Interest: The authors declare no conflict of interest.

\section{References}

1. Baldan, A. Adhesively-bonded joints and repairs in metallic alloys, polymers and composite materials: Adhesives, adhesion theories and surface pretreatment. J. Mater. Sci. 2004, 39, 1-49. [CrossRef]

2. Hollaway, L.C.; Cadei, J. Progress in the technique of upgrading metallic structures with advanced polymer composites. Prog. Struct. Eng. Mater. 2002, 4, 131-148. [CrossRef]

3. Islam, M.S.; Tong, L.; Falzon, P.J. Influence of metal surface preparation on its surface profile, contact angle, surface energy and adhesion with glass fibre prepreg. Int. J. Adhes. Adhes. 2014, 51, 32-41. [CrossRef]

4. Forsgren, A.; Knudsen, O.Ø. Corrosion Control through Organic Coatings, 2nd ed.; CRC Press: Boca Raton, FL, USA, 2017; pp. 137-147.

5. Qi, J.T.; Hashimoto, T.; Walton, J.R.; Zhou, X.; Skeldon, P.; Thompson, G.E. Trivalent chromium conversion coating formation on aluminium. Surf. Coat. Technol. 2015, 280, 317-329. [CrossRef]

6. Svoboda, J.; Kudlacek, J.; Kreibich, V.; Legutko, S. Alternative Methods of Chemical Pre-Treatment on Hot-Dip Galvanization Surface for Adhesion Organic Coatings. In Advances in Manufacturing, 1st ed.; Hamrol, A., Ciszak, O., Legutko, S., Jurczyk, M., Eds.; Springer: Gewerbestrasse, Switzerland, 2018; pp. 687-695. 
7. Iqbal, D.; Rechmann, J.; Sarfraz, A.; Altin, A.; Genchev, G.; Erbe, A. Synthesys of ultrathin Poly (methyl methacrylate) model coatings bound via organosilanes to zinc and investigation of their delamination kinetics. ACS Appl. Mat. Interfaces 2014, 6, 18112-18121. [CrossRef] [PubMed]

8. Harb, S.V.; Cerrutti, B.M.; Pulcinelli, S.H.; Santilli, C.V.; Hammer, P. Siloxane-PMMA hybrid anti-corrosion coatings reinforced by lignin. Surf. Coat. Technol. 2015, 275, 9-16. [CrossRef]

9. Fu, C.; Zhang, T.X.; Cheng, F.; Cui, W.Z.; Chen, Y. Double-Layer Coating Films Prepared from Water-Borne Latexes of Acrylate-Vinylidene Chloride Copolymers: Investigating Their Heavy-Duty Anticorrosive Properties. Ind. Eng. Chem. Res. 2014, 53, 4534-4543. [CrossRef]

10. Hidetoshi, Y. Stabilization of the polymer-metal interface. Prog. Org. Coat. 1996, 28, 9-15.

11. Yuan, Y.; Hays, M.P.; Hardwidge, P.R.; Kim, J. Surface characteristics influencing bacterial adhesion to polymeric substrates. RSC Adv. 2017, 7, 14254-14261. [CrossRef]

12. Raj, R.M.; Raj, V. Fabrication of superhydrophobic coatings for combating bacterial colonization on $\mathrm{Al}$ with relevance to marine and medical applications. J. Coat. Technol. Res. 2018, 15, 51-64.

13. Wang, Z.; Elimelech, M.; Lin, S. Environmental applications of interfacial materials with special wettability. Environ. Sci. Technol. 2016, 50, 2132-2150. [CrossRef] [PubMed]

14. Ali, U.; Karim, K.J.B.A.; Buang, N.A. A review of the properties and applications of poly (methyl methacrylate) [PMMA]. Polym. Rev. 2015, 55, 678-705. [CrossRef]

15. Fang, J.; Wang, C.; Li, Y.; Zhao, Z.; Mei, L. Comparison of bacterial adhesion to dental materials of polyethylene terephthalate (PET) and polymethyl methacrylate (PMMA) using atomic force microscopy and scanning electron microscopy. Scanning 2016, 38, 665-670. [CrossRef] [PubMed]

16. Tan, H.L.; Lin, W.T.; Tang, T.T. The use of antimicrobial-impregnated PMMA to manage periprosthetic infections: Controversial issues and the latest developments. Int. J. Artif. Organs 2012, 35, 832-839. [CrossRef] [PubMed]

17. Tamayo, L.A.; Zapata, P.A.; Vejar, N.D.; Azócar, M.I.; Gulppi, M.A.; Zhou, X.; Thompson, G.; Páez, M.A. Release of silver and copper nanoparticles from polyethylene nanocomposites and their penetration into Listeria monocytogenes. Mater. Sci. Eng. C 2014, 40, 24-31. [CrossRef] [PubMed]

18. Tamayo, L.; Azócar, M.; Kogan, M.; Riveros, A.; Páez, M. Copper-polymer nanocomposites: An excellent and cost-effective biocide for use on antibacterial surfaces. Mater. Sci. Eng. C 2016, 69, 1391-1409. [CrossRef] [PubMed]

19. Tamayo, L.; Acuña, D.; Riveros, A.L.; Kogan, M.J.; Azocar, M.I.; Páez, M.; Leal, M.; Urzúa, M.; Cerda, E. Porous Nanogold/Polyurethane Scaffolds with Improved Antibiofilm, Mechanical, and Thermal Properties and with Reduced Effects on Cell Viability: A Suitable Material for Soft Tissue Applications. ACS Appl. Mater. Interfaces 2018, 10, 13361-13372. [CrossRef] [PubMed]

20. Lyutakov, O.; Goncharova, I.; Rimpelova, S.; Kolarova, K.; Svanda, J.; Svorcik, V. Silver release and antimicrobial properties of PMMA films doped with silver ions, nano-particles and complexes. Mater. Sci. Eng. C 2015, 49, 534-540. [CrossRef] [PubMed]

21. Petrochenko, P.E.; Zheng, J.; Casey, B.J.; Bayati, M.R.; Narayan, R.J.; Goering, P.L. Nanosilver-PMMA composite coating optimized to provide robust antibacterial efficacy while minimizing human bone marrow stromal cell toxicity. Toxicol. In Vitro 2017, 44, 248-255. [CrossRef] [PubMed]

22. Borse, S.; Temgire, M.; Khan, A.; Joshi, S. Photochemically assisted one-pot synthesis of PMMA embedded silver nanoparticles: Antibacterial efficacy and water treatment. RSC Adv. 2016, 6, 56674-56683. [CrossRef]

23. Azioune, A.; Marcozzi, M.; Revello, V.; Pireaux, J.J. Deposition of polysiloxane-like nanofilms onto an aluminium alloy by plasma polymerized hexamethyldisiloxane: Characterization by XPS and contact angle measurements. Surf. Interface Anal. 2007, 39, 615-623. [CrossRef]

24. Davies, M.C.; Lynn, R.A.P.; Hearn, J.; Paul, A.J.; Vickerman, J.C.; Watts, J.F. Surface Chemical Characterization Using XPS and TOF-SIMS of Latex Particles Prepared by the Emulsion Copolymerization of Functional Monomers with Methyl Methacrylate and 4-Winylpyridine. Langmuir 1995, 11, 4313-4322. [CrossRef]

25. Watts, J.F.; Leadley, S.R.; Castle, J.E.; Biomfield, C.J. Adsorption of PMMA on Oxidized Al and Si Substrates: An Investigation by High-Resolution X-ray Photoelectron Spectroscopy. Langmuir 2000, 16, 2292-2300. [CrossRef]

26. Ozge, O.; Eda, A.A.; Vasif, H.; Nesrin, H. Surface characterization and radical decay studies of oxygen plasma-treated PMMA films. Surf. Interface Anal. 2013, 45, 844-853. [CrossRef] 
27. Amor, B.S.; Baud, G.; Jacquet, M.; Nansé, G.; Fioux, P.; Nardin, M. XPS characterization of plasma-treated and alumina-coated PMMA. Appl. Surf. Sci. 2000, 153, 172-183. [CrossRef]

28. Beamson, G. Conformation and orientation effects in the X-ray photoelectron spectra of organic polymers. J. Electron. Spectrosc. Relat. Phenom. 2001, 121, 163-181. [CrossRef]

29. Wei, Y.; Chen, Y.; Liu, P.; Gao, Q.; Sun, Y.; Huang, C. Surface modification of hydrophobic PMMA intraocular lens by the immobilization of hydroxyethyl methacrylate for improving application in ophthalmology. Plasma Chem. Plasma Process. 2011, 31, 811-825. [CrossRef]

30. DeQueiroz, G.A.; Day, D.F. Antimicrobial activity and effectiveness of a combination of sodium hypochlorite and hydrogen peroxide in killing and removing Pseudomonas aeruginosa biofilms from surfaces. J. Appl. Microbiol. 2007, 103, 794-802. [CrossRef] [PubMed]

31. Bruzaud, J.; Tarrade, J.; Coudreuse, A.; Canette, A.; Herry, J.M.; de Givenchy, E.T.; Darmanin, T.; Guittard, F.; Guilbaud, M.; Bellon-Fontaine, M.N. Flagella but not type IV pili are involved in the initial adhesion of Pseudomonas aeruginosa PAO1 to hydrophobic or superhydrophobic surfaces. Colloids Surf. B 2015, 131, 59-66. [CrossRef] [PubMed]

32. Das, B.; Dash, S.K.; Mandal, D.; Ghosh, T.; Chattopadhyay, S.; Tripathy, S.; Das, S.; Dey, S.K.; Das, D.; Roy, S. Green synthesized silver nanoparticles destroy multidrug resistant bacteria via reactive oxygen species mediated membrane damage. Arab. J. Chem. 2017, 10, 862-876. [CrossRef]

33. Shchukin, D.G.; Zheludkevich, M.; Yasakau, K.; Lamaka, S.; Ferreira, M.G.S.; Möhwald, H. Layer-by-Layer Assembled Nanocontainers for Self-Healing. Corrosion Protection. Adv. Mater. 2006, 18, 1672-1678. [CrossRef]

34. Gonzalez, E.; Pavez, J.; Azocar, I.; Zagal, J.H.; Zhou, X.; Melo, F.; Thompson, G.E.; Páez, M.A. A silanol-based nanocomposite coating for protection of AA-2024 aluminum alloy. Electrochim. Acta 2011, 56, 7586-7595. [CrossRef]

35. Wang, W.; Chen, X.; Efrima, S. Silver nanoparticles capped by long-chain unsaturated carboxylates. J. Phys. Chem. B 1999, 103, 7238-7246. [CrossRef]

Sample Availability: Samples of the PMMA coating and treated aluminum alloy are available from the authors.

(C) 2018 by the authors. Licensee MDPI, Basel, Switzerland. This article is an open access article distributed under the terms and conditions of the Creative Commons Attribution (CC BY) license (http://creativecommons.org/licenses/by/4.0/). 